\title{
Lady Emma Hamilton's Attitudes Renewed: Art gallery performance project
}

The Queen’s House, overlooking the Thames at Greenwich, is responsible for the handsome vista leading down to the river being a sight flanked by Christopher Wren's famous domes. It was built originally for Queen Anne, the consort of James I, by the seventeenth-century polymath Inigo Jones. Until being appointed Surveyor of the King's Works, he was most prominent for organizing court entertainments, and it is no accident that his designs for the House have a theatrical feel to them. Later, when Wren was commissioned to redevelop the site in front of it as the Royal Greenwich Naval Hospital, he was instructed to do so without obscuring Queen Mary’s cherished view of the river, hence the location of the major buildings on either side of an axis that allowed the vantage point to be kept, enhanced by Wren's work. The effect remains rather stunning: a charming Renaissance residence that looks past the twin domes and lines up with the more modern architecture of Canary Wharf on the opposite bank. The majestic seventeenth-century house sits elegantly between the River Thames and Greenwich Park. It attracts visitors from all over the world interested in its classical Renaissance architecture and the National Maritime Museum's outstanding fine art collection displayed in its many rooms and corridors. What more could a major London tourist attraction need?

Bearing in mind this legacy - Jones’ theatricality, Wren’s corrupted master plan and the historical role of the house as a project for prominent female royals of various dispositions - the opportunity to perform at the house (now part of Royal Museums Greenwich, RMG) lends itself to themes of spectacle and women's expression. Accordingly, our performance project Attitudes Renewed took place at The Queen’s House over the weekend of 15 and 16 February 2014 to reconcile these ideas. 
The project was a collaboration between live art collective Akleriah

(www.akleriah.com/index1.html), film-maker Jason Wen, and myself as theatre director. It was performed by drama students from the University of Greenwich, with the support and cooperation of the museum. This article concerns the issues that arise when dealing with the complicated mix of a historical site, visitor expectation and the museum's mission, and how these give rise to directorial and design challenges when creating a performance that will respond to the legacy of the space.

\section{Negotiating the venue}

To entice a greater number of visitors, especially those who might usually avoid a trip to anything considered historical, Louise Simkiss, the programmes manager at RMG, commissioned the performance to tie in with the current display of engravings of Lady Hamilton's Attitudes by Friedrich Rehberg (1800). Simkiss hopes that the physical embodiment of people from the past brings the house to life and piques the curiosity of its visitors to find out more. The Attitudes refers to Emma Hamilton's celebrated solo performance where she adopted emotionally charged poses based on classical Greek and Roman sculptures. We offered visitors to The Queen’s House a contemporary re-imagining of Emma's world and an insight into the rags to riches story of this iconic figure, who is often only remembered for being the mistress of Admiral Lord Nelson. Instead, she was arguably the first female performance artist and consequently of interest to current theatre makers and students, as well as the general public. How then to manifest a fair representation of this contentious woman and imbue her presence with appeal and intrigue in a given space, particularly when 
her form is already present in paintings and etchings on the walls that delineate that space, alongside other ghostly faces and suspended moments in time?

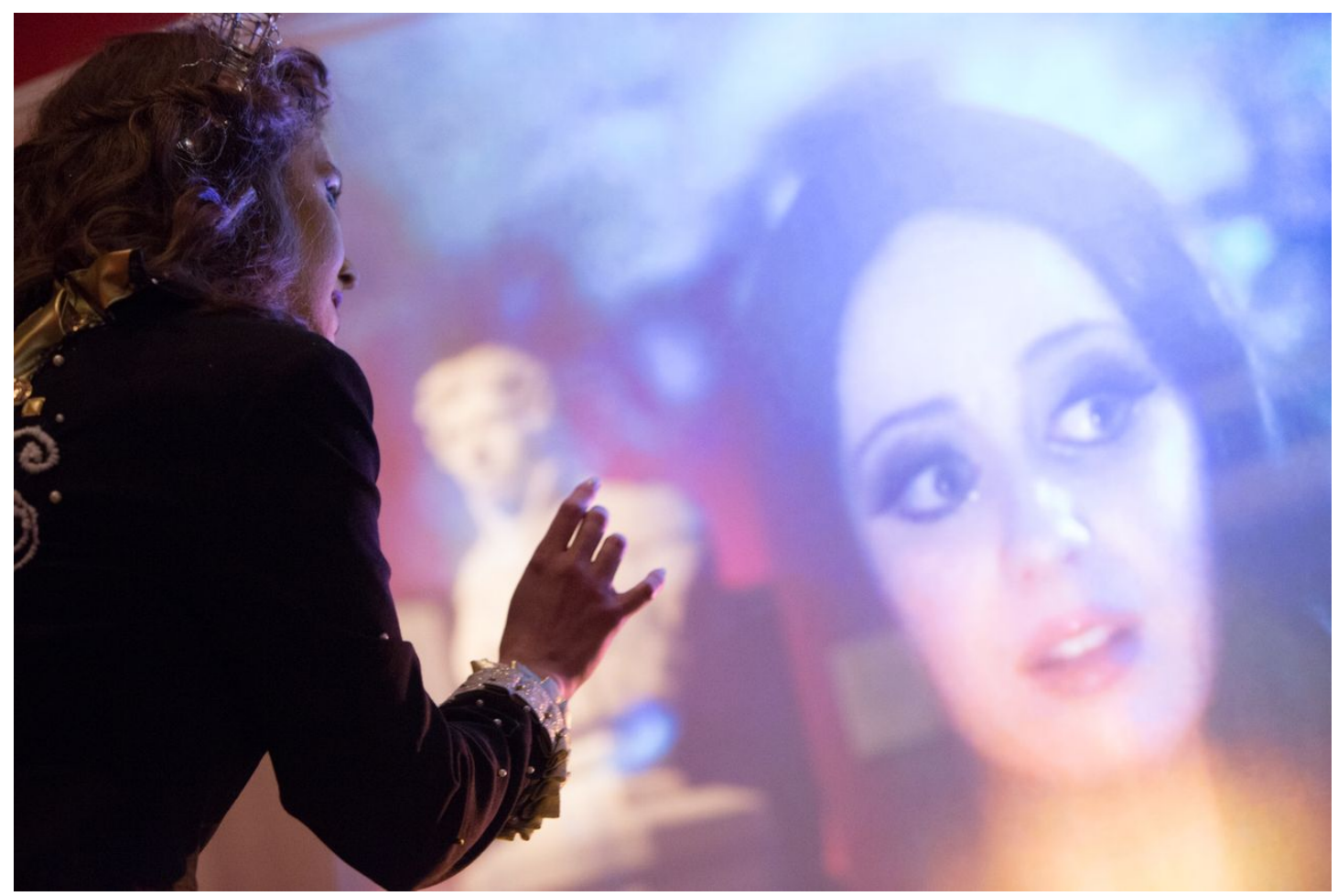

Figure 1: Young Emma and Close-up. Photograph by Jason Wen, Akleriah, courtesy of RMG

Costumed characters who directly address the audience are an entertaining and educational tool for gallery and museum theatre, and companies such as Spectrum and Spaniel in the Works create an entire production related to an exhibit. Akleriah's approach is far more abstract and choreographic. They play with the space and its potential for exchange: their work is site specific and the audience is usually free to move around so that, wherever they stand, they will experience a different, personal view, as an extension of the behaviours they ordinarily undertake in that gallery or other setting. Performers interact with the audience by coming very close or needing them to move aside as they pass, provoking an alert, participatory atmosphere within which the visual spectacle unfolds. In Attitudes Renewed, Emma's shifting poses and bursts of elegiac singing allowed a constant central focus. The scenography was 
created by film projection on pieces of fabric moving around her and by the presence of seven other characters from her life. Their gestures and occasional text interconnected with the imagery of the film, with Emma, with each other or with individual audience members. This visual density worked well for a short piece intended for a semi-transitory, partly non-English-speaking tourist audience. Attitudes Renewed lasted only fifteen minutes, performed a total of ten times over the weekend; thus its duration deliberately prompted the sense that watching a live event was one part of the overall possible gallery visitor experience, as requested by the venue's programmes manager. Inspired by an artistically mediated encounter with Emma Hamilton, her admirers and high-society critics, who and what else will the visitor seek within the house and the museum next door?

\section{A process fit for a Queen ('s House)}

As a theatre director I was excited to be involved creatively in the project and interested to learn about Akleriah’s design concepts and style, which is strongly rooted in their Russian and Czech heritage but expressed in a flamboyant live art form. Elaborate costume and make-up is an important element in their work, designed and created by Anna Kompaniets. As a lecturer I was able to suggest student performers who might be suitable and thus facilitate a learning opportunity for those students. The role of the charismatic Emma was cast first and it remained to decide which other apparitions to resurrect in the gallery: the question of who else might tantalize the visitors' imagination and serve a purpose for the semiotic and visual scope of the work. 
Lenka Horakova is the conceptualist half of Akleriah and carefully steered the early part of the process by asking each of the performers which of the themes she had identified to do with Emma - such as intrigue, status, passion, rivalry, loneliness they personally connected to. This provoked individual commitment and a physical way into the material. Playing two specific 'qualities' through expressive movement for an extended period of time allowed a depth of emotion to emerge, and these improvisations formed the basis of the characters used in the final piece. We asked, what can we learn from Emma now? How do we relate to her? At the same time, factual research was drawn from sources such as Flora Fraser's biography Beloved Emma (2003) and from Emma's own accounts in a collection of her letters.

Performers were required to both absorb hard facts and to physically extemporize in rehearsal, all the while anticipating that there would be a particular gallery ambience to do with viewing or re-seeing throughout the performance itself and also acknowledging that Emma's fortune was largely shaped by how others in society saw her at the time. Therefore we included influential men and women in her life, such as her obsessive lover Charles Greville who is seen shaking hands with her next benefactor William Hamilton, and Lady X, a representative of high-society women, who scorned Emma's social climbing and provided witty comments such as Lady Palmerston's ‘Her voice is vulgar and she and Sir William are rather too fond'. By contrast, Queen Maria Carolina of Italy provided a powerfully supportive presence despite her own moments of grief and anger, glimpsed with emotional intensity in the final performances. She respected Emma's judgements politically and in return gave approval for the erstwhile courtesan to marry William Hamilton, then Ambassador of Naples; this became an important moment of spoken text in the performance. The presence of Emma's hardworking, proud mother and a carefree young Emma who 
marvelled at her future self allowed contemporaneous realities in the gallery space, appreciating her humble beginnings and the possibility for change. As well as Emma, the other actors were asked to create moments of contemporary 'attitudes' within their character's physical vocabulary, and this worked especially well for young Emma when she moved between innocence, awe and a more knowing, self-assured sequence of poses that could befit a modern female.

With the amused agreement of the venue programmer, Attitudes Renewed deliberately omitted Nelson, whose presence was already felt to be large enough in the public imagination as well as on the gallery walls and in the Maritime Museum next door. The passing presence of the painter Romney, who was indeed Emma's friend and immortalizer through his work, did seem a natural inclusion in the process. It proved satisfying to watch the adoring and enthusiastic artist at work as the film slowly revealed Emma’s face as Circe (1782), a sorceress from Greek mythology. By the performers' changing manipulation of fabric pieces, discovered through rehearsal experiments, this beautiful image appeared to gently enlarge and then multiply onto several surfaces before finally smothering the face of the 'real life' Emma. These fabrics were at times part of a costume, William's trousers or Emma's shawls for example, as well as surfaces on which to project. Romney's fiery painting Lady Hamilton as Cassandra (-) and the more wistful Ariadne (1785) were both on view in the main performance gallery in which the piece occurred, fixed references to Emma’s many guises while Circe disappeared before our eyes.

The first part of the film became a close-up monologue by Emma compiled from extracts of Lady Hamilton's original letters to Greville. It switched from her time in 
London to Naples and between sadness and anger at her lover's rejection, and lastly to pride at her newly found celebrity status. The timely integration of video images and costumed characters was found to establish an acceptable interplay between technology and live performance. The tangible, breathing Emma arrived into the space only once her filmed speech had begun, watched or ignored by other characters from her life as appropriate. Subsequent images were intentionally fragmentary and refracted to reflect Emma's shifting surroundings and experiences: the trees that echoed St James’ Park where she had been paraded as a courtesan, for instance, or a smoking volcano from Italian travels. In rehearsal, we found how specific characters respond to the mood evoked by these images, as individuals and at times en masse. A set of tiny figures flickering on a Greek vase, for example, became a kaleidoscopic image on layers of fabric while the physical ensemble suggested a chattering, decadent party, catching a bewildered Emma in its dancing and mayhem.

\section{Outcomes and reaction}

It was at the three on-site rehearsals at The Queen's House with final costumes that the piece fully emerged and understood its territory. The stately, semi-lit North East Parlour was at first intimidating for some of the performers, and they had to overcome the feelings of shyness or vulnerability that the space triggered. When people arrived as planned (or drifted in unexpectedly) to watch the first Saturday afternoon performance, the intense, introspective work in rehearsal paid off. Characters knew themselves well enough to respond in the moment to the presence of audience members, making eye contact, moving through them, performing the choreography, song and text with conviction. Interestingly, the film projection enhanced the fluidity 
of the piece, reflecting the changeable landscape of Emma's life and strangely suiting the transitory feel of the art gallery. For me the most exciting moments were clashes or other combinations: when the Queen cried and stomped furiously past while Emma sang an extract from the charming, romantic ballad 'On Wings of Song' (Mendelssohn, 1834), or when she gave an 'attitude' of joy in front of a stoney beach image on film as it moved towards the audience, or the overlap between William's action of sadly cradling his lost child and the cruel sound of party laughter.

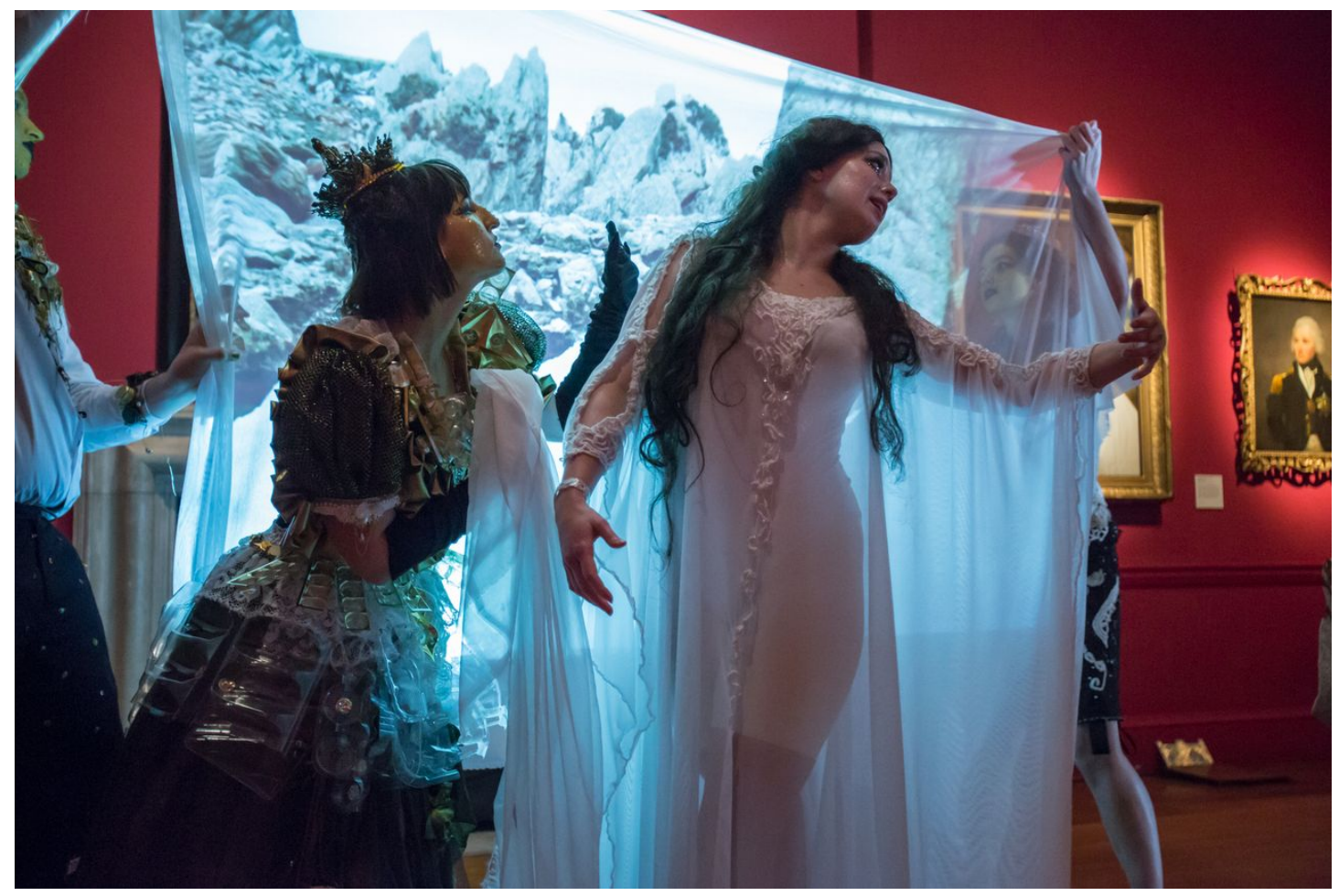

Figure 2: Queen and Emma, Stones. Photograph by Jason Wen, Akleriah, courtesy of RMG

Around 350 people saw Attitudes Renewed, with each performance averaging around 30 to 40 people. It was curious how some of the ten performances were stronger than others, an inconsistency that reflected the changing mood of the situation. The student performers learnt from repeating the piece over so many times that each time they had to win the trust of the audience afresh, through listening as sensitive actors and at the same time committing wholeheartedly to the material and its physical and emotional 
delivery. Being within an unsettling proximity to a standing audience works when the audience relaxes and becomes somehow complicit, in a state of tension that is expectant without feeling uncomfortable. Feedback written on audience comments cards ranged from 'beautiful', 'intriguing', 'magical atmosphere' to 'an interesting addition to the day, if a little odd'. Many commented on the creative use of fabric and film, others on the 'lovely voice' of Emma and how 'the play brought the gallery alive’. Others were more effusive with ‘enjoyable... thought-provoking’ and 'wonderful costumes'.

A favourite comment was 'Very good... ghost like' as for me it pinpointed an inherent feature of this unusual work. As a theatre director with a special interest in movement and physicality, I enjoyed working with Horakova and Kompaniets to shape the material and direct the performers, and I noticed what is perhaps a cultural distinction of the Akleriah approach. By instructing the actors early in rehearsal to 'go deep', the work has a certain radiance and indeed otherwordliness that is effective in a non-theatre space. The realization of these real-life ghosts worked in the immersive environment when the audience was standing but less so when they sat down. The venue is obliged to offer folding seats for visitors who need them and these were occasionally used. For one performance, six seats were taken and placed in the space and this created a ripple effect of several more people sitting on the floor, adults as well as children. This redesigned the space and its possibilities. One of the performers later remarked 'it felt incredibly different when they were sitting down. It created a fourth wall, a barrier between them and us ...the energy dropped'. She found it harder to entice the watchers into their world once they were on another physical level. 
The students also learnt from an impromptu experience in the splendid, perfectly proportioned Great Hall. Photographs were planned once the cast had exited from the penultimate gallery show into this next room, with Jones’ stunning black and white marble floor and high ceiling. As the enigmatic characters moved slowly between poses, improvising gestures and changes of gaze, a new crowd gathered to watch them at floor level and from the surrounding wooden balcony above. There was a sense that this extra performance could have continued for the rest of the day, with people coming, watching, and then leaving. The Visitors Services team reported that The Queen’s House had over 1200 people that weekend, around 500 on the Saturday and 700 on the Sunday, which is way above their usual headcount.

The purpose of the performance, the bringing alive of character and space, meant that Lady Hamilton's Attitudes Renewed attempted something rather radical in a space that might be conceived as deeply conservative. In doing so, it captured the spirit of its subject but also extends the imagination about the possibilities of spaces steeped in heritage. Modern projection technologies, and live art with a nod to Inigo Jones' like theatricality, create new possibilities for the representation of history in a museum context without depending on obvious storytelling, and remind the casual visitor that the rooms they visit are not just exhibition spaces. Certainly one comment card read 'Fabulous... please keep up this kind of event', an encouraging response to this ambitious interdisciplinary project.

\section{Reference}

Fraser, F. (2003), Beloved Emma: The Life of Emma, Lady Hamilton, London: John Murray. 